\title{
Residual effect of nCPAP applied for part of the night in patients with obstructive sleep apnoea
}

\author{
V. Hers*, G. Liistro*, M. Dury**, Ph. Collard*, G. Aubert**, D.O. Rodenstein*
}

Residual effect of $n C P A P$ applied for part of the night in patients with obstructive sleep apnoea. V. Hers, G. Liistro, M. Dury, Ph. Collard, G. Aubert, D.O. Rodenstein. (CERS Journals Ltd 1997.

ABSTRACT: The aim of the present study was to assess whether nasal continuous positive airway pressure (nCPAP) treatment, applied for only a few hours at the beginning of the night, has any residual effect on sleep and breathing during the ensuing hours of unassisted sleep in patients with obstructive sleep apnoea syndrome (OSAS).

In 27 patients with newly-diagnosed OSAS, effective nCPAP was applied during the first part of the night and then withdrawn. Polysomnographic parameters after nCPAP withdrawal were compared with those of the corresponding part of the diagnostic polysomnography performed a few days or weeks before and with those of the first part of night on nCPAP.

After $255 \pm 63$ (mean \pm SD) min of sleep with normalization of sleep and breathing parameters under nCPAP, there was partial improvement of OSAS severity during the remaining $124 \pm 56$ min of nocturnal sleep without treatment; mean oxygen saturation, desaturation index (equivalent to the apnoea/hypopnoea index) and movement arousal index all improved significantly with respect to the diagnostic night $(p=0.001)$. This improvement was not accounted for by a change in sleep architecture.

We conclude that there is an improvement in severity of obstructive sleep apnoea syndrome after only $4 \mathrm{~h}$ of nasal continuous positive airway pressure. This carryover effect could explain why a number of patients with obstructive sleep apnoea syndrome apply nasal continuous positive airway pressure for only part of the night or not every night.

Eur Respir J 1997; 10: 973-976.
*Pneumology and **EEG Units, Cliniques Universitaires Saint Luc, Université Catholique de Louvain, Brussels, Belgium.

Correspondence: D.O. Rodenstein Service de Pneumologie Cliniques Saint Luc Av Hippocrate 10 1200 Brussels

Belgium

Keywords: Compliance nasal continuous positive airway pressure sleep apnoea syndrome

Received: July 51996

Accepted after revision December 51996

Partly supported by grants Nos. 9.4547 .93 and 9.4530 .95 from the Belgian Fonds de la Recherche Scientifique Médicale.
Nasal continuous positive airway pressure (nCPAP) therapy is currently considered as the best treatment for obstructive sleep apnoea syndrome (OSAS). Since its description in 1981, many studies have shown that it normalizes both sleep and breathing, and improves daytime alertness in most patients [1-3].

Because the treatment is somewhat bulky and cumbersome, a great deal of commitment is required on the part of the patient, and compliance is the key to sucess $[4,5]$. Recent studies suggest that nCPAP use approaches at best $4.5 \mathrm{~h} \cdot \mathrm{night}^{-1}$ but may be even lower [6-9]. Nevertheless, it has been shown that a mere $3 \mathrm{~h}$ of nCPAP treatment per night may improve daytime functions [10]. We have found a minority of patients who use nCPAP for as little as 2-3 h.day-1 and yet remain on therapy for years, suggesting that they derive enough subjective benefit from such incomplete application of therapy [11]. These findings suggest that at least cognitive performance and quality of life of the patients can be improved by nCPAP treatment applied during only part of the night. However, the minimal duration of therapy remains to be established.

The purpose of the present study was to assess whether nCPAP therapy, applied for a few hours at the beginning of the night, had any residual effect on the severity of OSAS during the ensuing hours of unassisted nocturnal sleep in newly-diagnosed patients with OSAS.

\section{Methods}

\section{Polysomnography}

All-night polysomnography (PSG) was performed and scored according to standard criteria as described previously [12]. Briefly, electroencephalogram (EEG), electrooculogram (EOG) and submental electromyogram (EMG) were obtained from surface electrodes using standard techniques. Airflow was monitored by three thermocouples linked to independent channels, and placed in front of the mouth and each nostril. Respiratory movements were assessed by a thoracic strain gauge. Breathing sounds were recorded by a microphone glued to the neck. Electrocardiogram (ECG) was obtained from two electrodes placed on the chest. Transcutaneous oxygen saturation $\left(\mathrm{Sa}, \mathrm{O}_{2}\right)$ was recorded by pulse oximetry (Nellcor N-100, Hayward, CA, USA) using a finger probe. Sleep variables were scored manually, according to standard criteria, in 30s epochs [12].

A movement arousal (MA) was defined as the abrupt appearance of an alpha rhythm in the EEG during a sleep 
epoch, accompanied by an increase in EMG activity lasting for at least $2 \mathrm{~s} \mathrm{[12].} \mathrm{The} \mathrm{movement} \mathrm{arousal} \mathrm{index}$ (MAI) is the number of MA $\mathrm{h}^{-1}$ of sleep.

An apnoea was defined as complete cessation of airflow for $10 \mathrm{~s}$ or more. Apnoea is classified as central, obstructive or mixed according to absence or presence of breathing efforts. Hypopnoea was defined as any decrease in $\mathrm{Sa}_{2} \mathrm{O}_{2}$ greater than $4 \%$, associated with a reduction, but not cessation, of oronasal flow. The desaturation index (DI) was the number of $\geq 4 \%$ desaturations per hour of sleep, related to abrupt reductions or cessation of oronasal flow signal deflections, and was taken as the apnoea-hypopnoea index (AHI).

\section{Subjects}

The OSAS subjects were recruited from a population of patients referred for suspicion of OSAS, who underwent a full-night PSG (night 1). OSAS was diagnosed when the DI was $\geq 15$. A trial of nCPAP was offered to OSAS patients having DI $\geq 20$, with MAI $\geq 24$ or disabling daytime sleepiness. On this basis, 27 OSAS patients were enrolled in the study. They were middle-aged $(49 \pm 9 \mathrm{yrs})$, obese (body mass index $\left.(\mathrm{BMI})=33 \pm 7 \mathrm{~kg} \cdot \mathrm{m}^{-2}\right)$ and predominantly male (26 males and 1 female). They had a wide range of severity of sleep-disordered breath-

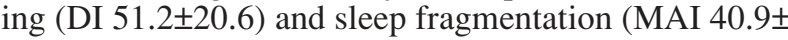
15.2). They had an increased proportion of stage 1 nonrapid eye movement (NREM) sleep, mainly at the expense of stages $3-4$, and their mean $(88 \pm 6 \%)$ and minimal $(64 \pm 12 \%) \mathrm{Sa}_{\mathrm{a}} \mathrm{O}_{2}$ were abnormally low.

\section{Study design}

After 2-3 nights on nCPAP treatment at low pressure $\left(5 \mathrm{cmH}_{2} \mathrm{O}\right)$ for habituation and adaptation to the interface device, as described previously [11], the patients underwent a second PSG under nCPAP (night 2). The pressure of nCPAP was increased in $1 \mathrm{cmH}_{2} \mathrm{O}$ steps in order to suppress snoring, MA and apnoea and/or hypopnoea. After about $4 \mathrm{~h}$ of treatment, nCPAP was discontinued, the mask was withdrawn, and the patients were allowed to fall asleep again. "Night 2a" was the part of the night during which nCPAP was applied, and "night $2 \mathrm{~b}$ " the remainder of the night after nCPAP withdrawal. Night 1 was also divided in 2 parts of equal duration to parts $\mathrm{a}$ and $\mathrm{b}$ of night 2 . DI, MAI, mean and minimal $\mathrm{Sa}_{\mathrm{O}} \mathrm{O}_{2}$, and sleep stages for night 1 , night $1 \mathrm{~b}$, and nights $2 \mathrm{a}$ and $\mathrm{b}$ were analysed independently. Polysomnographic parameters after nCPAP withdrawal (night 2b) were compared with those of the corresponding part of the diagnostic polysomnography (night $1 \mathrm{~b}$ ), and with those of the first part of night 2 (night 2a). Sleep architecture was compared between nights 1 and $2 \mathrm{a}$, and between nights $2 \mathrm{a}$ and $2 \mathrm{~b}$.

\section{Statistical analysis}

Values are presented as mean \pm SD. Student's t-test for paired samples was used to compare PSG parameters between different parts of the nights. Using Bonferroni's correction, a p-value less than 0.005 was considered significant. Linear regression analysis was used to evaluate the relationship between the respective changes in the variables, and a p-value less than 0.05 was considered significant.

\section{Results}

The interval between diagnostic and nCPAP polysomnographies was $33 \pm 16$ days. There was no relevant change in patients' complaints or BMI during this time. Therapeutic nCPAP pressure was $7.8 \pm 2.7 \mathrm{cmH}_{2} \mathrm{O}$ (range $5-15 \mathrm{cmH}_{2} \mathrm{O}$ ), and was reached $60 \pm 52 \mathrm{~min}$ after the start of night 2 recordings. Under nCPAP, the mean DI and MAI fell within the normal range (table 1). The mean and minimal $\mathrm{Sa}_{\mathrm{a}} \mathrm{O}_{2}$ increased to $95 \pm 2 \%$ and $86 \pm 8 \%$, respectively. Individual analysis showed normalization of all these parameters for 25 of the 27 patients. For the remaining two patients, only DI was not normalized but

Table 1. - Sleep and breathing data in patients with OSAS

\begin{tabular}{lccc}
\hline & Night 1 & Night 2a & p-value \\
\hline Mean $\mathrm{Sa}_{2} \mathrm{O}_{2} \%$ & $88 \pm 6$ & $95 \pm 2$ & $<0.001^{+}$ \\
Min $\mathrm{Sa}_{\mathrm{a}} \mathrm{O}_{2} \%$ & $64 \pm 12$ & $86 \pm 8$ & $<0.001^{+}$ \\
DI & $51.2 \pm 20.6$ & $10 \pm 11$ & $<0.001^{+}$ \\
MAI & $40.9 \pm 15.2$ & $9.1 \pm 6.0$ & $<0.001^{+}$ \\
TST min & $406 \pm 68$ & $255 \pm 63$ & - \\
Stage 1 \% & $26 \pm 19$ & $16 \pm 16$ & 0.005 \\
Stage 2 \% & $47 \pm 20$ & $49 \pm 17$ & 0.688 \\
Stage 3 \% & $3 \pm 3$ & $9 \pm 7$ & $<0.001^{+}$ \\
Stage 4 \% & $4 \pm 5$ & $9 \pm 10$ & 0.008 \\
REM \% & $20 \pm 5$ & $17 \pm 7$ & 0.140 \\
\hline
\end{tabular}

Values are presented as mean \pm SD. OSAS: obstructive sleep apnoea syndrome; Night 1: diagnostic night; night 2a: CPAP trial night on therapy; Min: minimal; $\mathrm{Sa}_{\mathrm{a}} \mathrm{O}_{2}$ : arterial oxygen saturation; DI: desaturation index; MAI: movement arousal index; TST: total sleep time; REM: rapid eye movement (sleep); nCPAP: nasal continuous positive airway pressure. ${ }^{+}$: significant difference, comparing night 1 and night $2 \mathrm{a}$.

Table 2. - Sleep and breathing data before, during and after nCPAP therapy in patients with OSAS

\begin{tabular}{|c|c|c|c|c|c|}
\hline & Night $1 \mathrm{~b}$ & Night $2 b$ & p-value & Night $2 \mathrm{a}$ & p-value \\
\hline Mean $\mathrm{Sa}_{\mathrm{a}} \mathrm{O}_{2} \%$ & $90 \pm 5.4$ & $94 \pm 3$ & $0.001^{+}$ & $95 \pm 2$ & $<0.005^{+}$ \\
\hline Min $\mathrm{Sa}_{\mathrm{a}} \mathrm{O}_{2} \%$ & $63 \pm 19.5$ & $80 \pm 12$ & $<0.001^{+}$ & $86 \pm 8$ & $<0.001^{+}$ \\
\hline DI & $58.4 \pm 20.3$ & $34.9 \pm 21.8$ & $<0.001^{+}$ & $10.4 \pm 10.9$ & $<0.001^{+}$ \\
\hline MAI & $45.6 \pm 21.1$ & $29.2 \pm 15.7$ & $0.001^{+}$ & $9.1 \pm 6.0$ & $<0.001^{+}$ \\
\hline TST $\min$ & $129 \pm 45$ & $124 \pm 56$ & 0.340 & $255 \pm 63^{\$}$ & - \\
\hline Stage $1 \%$ & $29 \pm 23$ & $30 \pm 24$ & 0.872 & $16 \pm 16$ & $<0.001^{+}$ \\
\hline Stage $2 \%$ & $44 \pm 20$ & $43 \pm 22$ & 0.803 & $49 \pm 17$ & 0.500 \\
\hline Stage $3 \%$ & $3 \pm 4$ & $2 \pm 4$ & 0.200 & $9 \pm 7$ & $<0.01$ \\
\hline Stage $4 \%$ & $2 \pm 4$ & $2 \pm 4$ & 0.529 & $9 \pm 10$ & $<0.001^{+}$ \\
\hline REM \% & $21 \pm 14$ & $24 \pm 19$ & 0.566 & $17 \pm 7$ & $<0.01$ \\
\hline
\end{tabular}

\#: night $2 \mathrm{~b}$ versus night $1 \mathrm{~b}$; : night $2 \mathrm{~b}$ versus night $2 \mathrm{a}$. Values are presented as mean \pm sD. Night $1 \mathrm{~b}$ : second part of diagnostic night; Night 2b: night after nCPAP withdrawal; Night 2a: night on nCPAP; \$: see text for the duration of therapeutic nCPAP level during night $2 \mathrm{a}^{+}{ }^{+}$: significant difference between groups indicated. For definitions see legend to table 1. 
clearly improved (84 vs 23 and 93 vs 22). Table 1 also shows the improvement in sleep architecture which was significant for stage 3 NREM sleep, and reached the limit of significance for stage 1 NREM sleep.

Table 2 shows that following $255 \pm 63$ min of sleep with nCPAP, there was a significant, though partial, improvement of the minimal and mean $\mathrm{Sa}_{2} \mathrm{O}_{2}$, DI and MAI during unassisted breathing for the remaining $124 \pm 56$ min of nocturnal sleep (night $2 b$ ). In other words, during night $2 b$, indices of OSAS severity were intermediate in value between (and significantly different from) those of night $1 \mathrm{~b}$ and of night $2 \mathrm{a}$. Sleep stage distribution was not significantly changed after nCPAP withdrawal (night 2b) compared to the corresponding part of diagnostic PSG (night 1b). No relationship was found between OSAS severity during the diagnosis night (night 1) or duration of nCPAP therapy during night $2 a$ and level of improvement of OSAS parameters on night $2 b$.

\section{Discussion}

This prospective study indicates that in patients with newly-diagnosed OSAS, some of the beneficial effects of nCPAP applied only during the first part of the night persist for at least $2 \mathrm{~h}$ after nCPAP withdrawal. The improvement was significant both in terms of DI and of MAI. However, after nCPAP withdrawal, these parameters failed to remain in the normal range for the majority of the 27 patients. Only two patients remained in the normal range in terms of DI, and seven in terms of MAI. No correlation was found between the improvement and the baseline DI or the baseline MAI.

These results were obtained in an unselected population of patients with OSAS, including moderate as well as severe OSAS cases, with characteristics similar to those usually observed in a typical OSAS population. On average, 1 month separated diagnostic and treatment nights. Since the BMI did not change during this period, and since our patients had quite severe OSAS [13], this delay cannot by itself explain the improvement seen on night $2 b$.

Sleep duration was satisfactory during both the diagnostic night (total sleep time (TST) $406 \pm 68 \mathrm{~min}$ ) and the night on nCPAP (TST $379 \pm 74$ min). However, sleep fragmentation was quite abnormal during the first night. As shown in table 2, all breathing parameters were normalized under nCPAP. The partial improvement of sleep-related disordered breathing observed after nCPAP withdrawal is certainly not accounted for by a change in sleep architecture. Indeed, as shown in table 2, sleep stage proportions did not change between night $1 \mathrm{~b}$ and night $2 b$.

To the best of our knowledge, such an immediate residual effect of nCPAP in newly-treated OSAS has never been described previously. Only one other fullydocumented split night study has been published. In patients receiving long-term nCPAP, RAUSCHER et al. [14] failed to find a less disturbed ventilation during sleep following use of nCPAP for only the first part of the night. However, they found that patients with more severe OSAS showed a significant reduction of events per hour of sleep. In the present study, we found no correlation between the severity of OSAS and the magnitude of improvement. Moreover, RAUSCHER et al. [14] did not assess an index of sleep fragmentation, such as the MAI, which is one of the parameters showing the higher residual effect of nCPAP in our study.

Four full night withdrawal studies have been published, with somewhat contradictory results. KRIBBS et al. [15] found a significant reduction in the respiratory disturbance index during the night off nCPAP, but failed to show a residual effect on hypersomnolence. SFORZA and LugARESI [16] performed a multiple sleep latency test (MSLT) in 30 OSAS patients after two consecutive PSGs, one with nCPAP and the other without, at baseline and after 1 year of treatment. They found a dramatic fall in mean sleep latency and a recurrence of disturbed ventilation on the first night off therapy; however, the subjects claimed that they did not feel sleepy. Along the same lines, Collop et al. [17] found no improvement of sleep-disordered breathing during 1 night without nCPAP in OSAS patients treated for 6 weeks. By contrast, some data exist suggesting that there is a residual effect of nCPAP, so that after nCPAP, OSAS returns to its pretreatment severity only after several days [18]. Recently, NosEDA et al. [19] reported a mild but statistically significant reduction of OSAS severity in 20 out of 39 patients after acute nCPAP weaning. They found that improvement correlated with reduction in BMI and baseline severity of OSAS.

As far as we know, all studies assessing such a residual effect of nCPAP after weaning have always involved groups of patients treated at home for several weeks [14-19]. In the present study, a residual positive effect was found after only a few hours of treatment. The patients were submitted to low-level nCPAP $\left(5 \mathrm{cmH}_{2} \mathrm{O}\right)$ for 2-3 nights before the nCPAP polysomnography (night 2 ). We cannot exclude the possibility that part of the improvement seen during night $2 b$ arose not only from effective treatment during night 2 a but also, at least partly, from a suboptimal therapeutic effect of the habituation nights. However, the effective nCPAP level was similar to the habituation night nCPAP level $\left(\approx 5 \mathrm{cmH}_{2} \mathrm{O}\right)$ in only four patients. Even if the improvement reported depends on a carry-over effect of the 2-3 nights, this does not detract from the main finding, i.e. nCPAP has a residual effect, be it acute (after $4 \mathrm{~h}$ ) or short-term (a couple of days).

It is debatable whether reduction in pharyngeal mucosal oedema, as observed previously, is the explanation for such a rapid and persistent effect. Indeed, increase in upper airway size, recently reported by MORTIMORE et al. [20] in regular nCPAP users, was dependent on compliance to therapy, and was mostly seen in patients using nCPAP for more than $6 \mathrm{~h} \cdot$ night $^{-1}$. By contrast, we observed no correlation between the magnitude of improvement and the duration of treatment. One possible explanation for our findings is the reduction in sleep fragmentation during the first part of the night. Sleep fragmentation is known to increase upper airway collapsibility [21]. Therefore, the reduction of the MAI under nCPAP may lead to a lower degree of susceptibility to upper airway occlusion during the first hours of unassisted sleep, and hence to a decrease in the DI and MAI. Charbonneau et al. [22] have shown that the duration and frequency of apnoeas increase throughout the night. If we consider that our patients began their "night" at $02.00 \mathrm{~h}$ (i.e. when nCPAP was discontinued) 
instead of at $22.00 \mathrm{~h}$, this may have contributed to the results observed.

The present results may help to explain recent, seemingly disappointing, data on long-term nCPAP compliance. Reports [6-8] relying on monitored nCPAP with hidden time clocks and/or mask pressure transducer recorders, have disclosed that treatment compliance with nCPAP is generally about $4 \mathrm{~h} \cdot \mathrm{night}^{-1}$. KRIBBS et al. [6] reported that 35 patients followed for 3 months used their device only $66 \%$ of the days for a mean time of $4.9 \mathrm{~h}$, which gives a mean daily compliance of $3.2 \mathrm{~h}$ [11]. ReEves-Hoche et al. [7] reported an effective nightly use of $4.3 \mathrm{~h}$. They found that compliance correlated with subjective initial complaints of daytime sleepiness. ENGLEMAN et al. [8] obtained similar results in 54 patients over the first 3 months after starting nCPAP therapy. More recently, we have shown [11] objectively in a large group of patients with a long follow-up, a compliance of more than $5 \mathrm{~h} \cdot \mathrm{day}^{-1}$. In this study, compliance correlated positively with MAI and negatively with age and $\mathrm{Sa}, \mathrm{O}_{2}$.

If, as our results show, sleep apnoea severity during the last hours of the night off nCPAP is lessened by the previous hours of nCPAP-assisted sleep, then patients could still derive a benefit from therapy applied during only part of the night. Since we have not assessed symptoms or long-term compliance in this group of patients, this remains hypothetical. However, this hypothesis is strengthened by the results of ENGLEMAN et al. [10], who have shown that after only $3.4 \mathrm{~h}$ of nCPAP therapy per night, daytime cognitive performance was significantly improved. This does not mean that patients should be encouraged to use nCPAP for only part of the night, nor that physicians should fail to make every effort to try to achieve a better compliance

In conclusion, we have shown that nasal continuous positive airway pressure applied for $4 \mathrm{~h}$ at the beginning of the night has a residual beneficial effect on obstructive sleep apnoea syndrome during the last part of the night, without nasal continuous positive airway pressure therapy.

Acknowledgement: The authors gratefully acknowledge the substantial help of M.P. Biettlot.

\section{References}

1. Sullivan CE, Issa FG, Berthon-Jones M, Eves L. Reversal of obstructive sleep apnoea by continuous positive airway pressure applied through the nares. Lancet 1981; 1: 862-865.

2. Sullivan CE, Issa FG, Berthon-Jones M, McCauley VB, Costas LJ. Home treatment of obstructive sleep apnoea with continuous positive airway pressure applied through a nose-mask. Bull Eur Physiopathol Respir 1984; 20: 49-54.

3. Berry RB, Block AJ. Positive nasal airway pressure eliminates snoring as well as obstructive sleep apnea. Chest 1984; 85: 15-20.

4. Collard P, Delguste P, Aubert G, Rodenstein DO. Continuous positive airway pressure: problems and limitations. In: Robert D, Make BJ, Léger P, Goldberg AI, Paulus J, Willig TN, eds. Home Mechanical Ventilation. Paris, Arnette Blackwell, 1995; pp. 193-201.

5. Hoffstein V, Viner S, Mateika S, Conway J. Treatment of obstructive sleep apnea with nasal continuous positive airway pressure: patient compliance, perception of benefits, and side-effects. Am Rev Respir Dis 1992; 145: 841-845.

6. Kribbs NB, Pack AI, Kline LR, et al. Objective measurement of patterns of nasal CPAP use by patients with obstructive sleep apnea. Am Rev Respir Dis 1993; 147: 887-895.

7. Reeves-Hoche MK, Meck R, Zwillich CW. Nasal CPAP: an objective evaluation of patient compliance. Am J Respir Crit Care Med 1994; 149: 149-154.

8. Engleman HM, Martin SE, Douglas NJ. Compliance with CPAP therapy in patients with the sleep apnoea/ hypopnoea syndrome. Thorax 1994; 49: 263-266.

9. Rauscher H, Formanek D, Popp W, Zwick H. Selfreported $v s$ measured compliance with nasal CPAP for obstructive sleep apnea. Chest 1993; 103: 1675-1680.

10. Engleman HM, Martin SE, Deary IJ, Douglas NJ. Effect of continuous positive airway pressure treatment on daytime function in sleep apnoea/hypopnoea syndrome. Lancet 1994; i(343): 572-575.

11. Pieters T, Collard P, Aubert G, Dury M, Delguste P, Rodenstein DO. Acceptance and long-term compliance with CPAP in patients with obstructive sleep apnoea syndrome. Eur Respir J 1996; 9: 939-944.

12. Collard P, Dury M, Delguste P, Aubert G, Rodenstein DO. Movement arousals and sleep-related disordered breathing in adults. Am J Respir Crit Care Med 1996; 154: 454-459.

13. Wittig RM, Romaker A, Zorick FJ, Roehrs TA, Conway WA, Roth T. Night-to-Night consistency of apneas during sleep. Am Rev Respir Dis 1984; 129: 244-246.

14. Rauscher H, Popp W, Wanke T, Zwick H. Breathing during sleep in patients treated for obstructive sleep apnea. Chest 1991; 100: 156-159.

15. Kribbs NB, Pack AI, Kline LR, et al. Effects of one night without nasal CPAP treatment on sleep and sleepiness in patients with obstructive sleep apnea. Am Rev Respir Dis 1993; 147: 1162-1168.

16. Sforza E, Lugaresi E. Daytime sleepiness and nasal continuous positive airway pressure therapy in obstructive sleep apnea syndrome patients: effects of chronic treatment and 1 night therapy withdrawal. Sleep 1995; 18: 195-201.

17. Collop NA, Block AJ, Hellard D. The effect of nightly nasal CPAP treatment on underlying obstructive sleep apnea and pharyngeal size. Chest 1991; 99: 855-860.

18. Collard P, Cornette P, Aubert G, Rodenstein DO. Sleep apnoea-hypopnoea syndrome: a polysomnographic study before and after prolonged continuous positive airway pressure therapy (Abstract). Eur Respir J 1992; 5: 21S.

19. Noseda A, Kempenaers C, Kerkhofs M, Houben JJ, Linkowski P. Sleep apnea after 1 year domiciliary nasal continuous positive airway pressure and attempted weight reduction: potential for weaning from continuous positive airway pressure. Chest 1996; 109: 138-143.

20. Mortimore IL, Kochhar P, Douglas NJ. Effect of chronic continuous positive airway pressure (CPAP) therapy on upper airway size in patients with sleep apnoea/hypopnoea syndrome. Thorax 1996; 51: 190-192.

21. Series F, Roy N, Marc I. Effects of sleep deprivation and sleep fragmentation on upper airway collapsibility in normal subjects. Am J Respir Crit Care Med 1994; 150(2): 481-485.

22. Charbonneau M, Marin JM, Olha A, Kimoff J, Levy $\mathrm{RD}$, Cosio MG. Changes in obstructive sleep apnea characteristics through the night. Chest 1994; 106: 1695-1701. 